\title{
Complete Evaluation of Dementia: PET and MRI Correlation and Diagnosis for the Neuroradiologist
}

\author{
(D).D. Oldan, (D)V.L. Jewells, (1)B. Pieper, and (1)T.Z. Wong
}

ow

\begin{abstract}
SUMMARY: This article will familiarize neuroradiologists with the pathophysiology, clinical findings, and standard MR imaging and PET imaging features of multiple forms of dementia as well as new emerging techniques. Cases were compiled from multiple institutions with the goal of improved diagnostic accuracy and improved patient care as well as information about biomarkers on the horizon. Dementia topics addressed include the following: Alzheimer disease, frontotemporal dementia, cerebral amyloid angiopathy, Lewy body dementia, Parkinson disease and Parkinson disease variants, amyotrophic lateral sclerosis, multisystem atrophy, Huntington disease vascular dementia, and Creutzfeldt-Jakob disease.
\end{abstract}

ABBREVIATIONS: $\mathrm{AD}=$ Alzheimer disease; $\mathrm{CAA}=$ cerebral amyloid angiopathy; $\mathrm{CBD}=$ corticobasilar degeneration; FTD $=$ frontotemporal dementia; $\mathrm{LBD}=$ Lewy body dementia; $\mathrm{MCl}=$ mild cognitive impairment; $\mathrm{MH}=$ microhemorrhages; $\mathrm{MSA}=$ multisystem atrophy; $\mathrm{PD}=$ Parkinson disease; $\mathrm{PSP}=$ progressive supranuclear palsy; rsfMRI = resting-state fMRI

$I_{\mathrm{m}}^{\mathrm{n}}$ patients who present with cognitive impairment, obtaining MR imaging is standard practice, but PET strengthens interpretation. Neurodegenerative syndromes are diagnosed by clinical findings/Lumbar Puncture markers and not pathology, and they may overlap. This overview of neurodegenerative syndromes and their MR imaging/PET appearances includes Alzheimer disease (AD), frontotemporal dementia (FTD), cerebral amyloid angiopathy (CAA), Lewy body dementia (LBD), Parkinson disease (PD), amyotrophic lateral sclerosis, multisystem atrophy (MSA), progressive supranuclear palsy (PSP), corticobasilar degeneration (CBD), Huntington disease, vascular dementia, and Creutzfeldt-Jakob disease. The discussion includes newer MR imaging techniques (resting-state fMRI [rsfMRI]/task-based MR imaging), DTI, and iron deposition as well as novel nuclear medicine agents. Our goal was familiarization of neuroradiologists with nuclear medicine and molecular imaging diagnoses and novel imaging techniques.

Received April 4, 2020; accepted after revision November 14.

From the Department of Radiology (J.D.O., V.L.J), University of North Carolina, Chapel Hill, North Carolina; Department of Radiology (B.P.), Richard L. Roudebush VA Medical Center, Indianapolis, Indiana; and Department of Radiology (T.Z.W.), Duke University Hospital, Durham, North Carolina.

Paper previously presented, in part, at: Annual AOCR Convention 2019, Merging Mind and Muscle, April 8-12, 2019, San Antonio, Texas.

Please address correspondence to Valerie L. Jewells, MD, University of North Carolina, 100 Manning Dr, 3324 Old Infirmary Building, Campus Box 7510, Chapel Hill, NC 27599-7510; e-mail: jewells@med.unc.edu

- Indicates open access to non-subscribers at www.ajnr.org

Indicates article with online supplemental data.

http://dx.doi.org/10.3174/ajnr.A7079
Institutional review board (University of North Carolina) approval and a waiver of patient consent was obtained (study No. 20-2089).

\section{Alzheimer Disease}

$\mathrm{AD}$, the second most common neurodegenerative disorder after stroke, affects $10 \%$ of the population older than 65 years of age, and it is the sixth leading cause of death with US annual costs of $\$ 236$ billion. Clinical symptom similarities hamper diagnosis, leading to a low $71 \%-87 \%$ sensitivity and $44 \%-71 \%$ specificity. ${ }^{1}$ Despite no cure, diagnosis is helpful because cholinesterase inhibitors delay cognitive decline, and there is the need for institutionalization and improved end-of-life planning. ${ }^{1}$

Molecular imaging modalities demonstrate elevated amyloid$\beta$ and $\tau$ proteins. Amyloid- $\beta$ impacts synaptic function, while age-accumulating $\tau$ neurofibrillary tangles cause neuroinflammation and neurodegeneration and finally dementia., ${ }^{2,3}$ Additional causations include inflammatory microglial (M2) and poor amyloid- $\beta$ clearance by astrocytes. ${ }^{3}$ Drugs targeting amyloid fail because of a long prodromal and asymptomatic inflammatory phase and other processes of $\mathrm{AD}$, suggesting an urgent need for earlier diagnosis and better surrogate markers. ${ }^{2-5}$ Preventative measures include exercise and appropriate sleep (impact glymphatic system amyloid and $\tau$ removal $)^{3,6}$ and diabetes and stress control (preventing inflammation and BBB disruption). ${ }^{3-7}$ Tau formation and neuronal damage cascade also occur in Parkinson, amyotrophic lateral sclerosis, multiple sclerosis, and Huntington disease (Online Supplemental Data). ${ }^{8}$ 


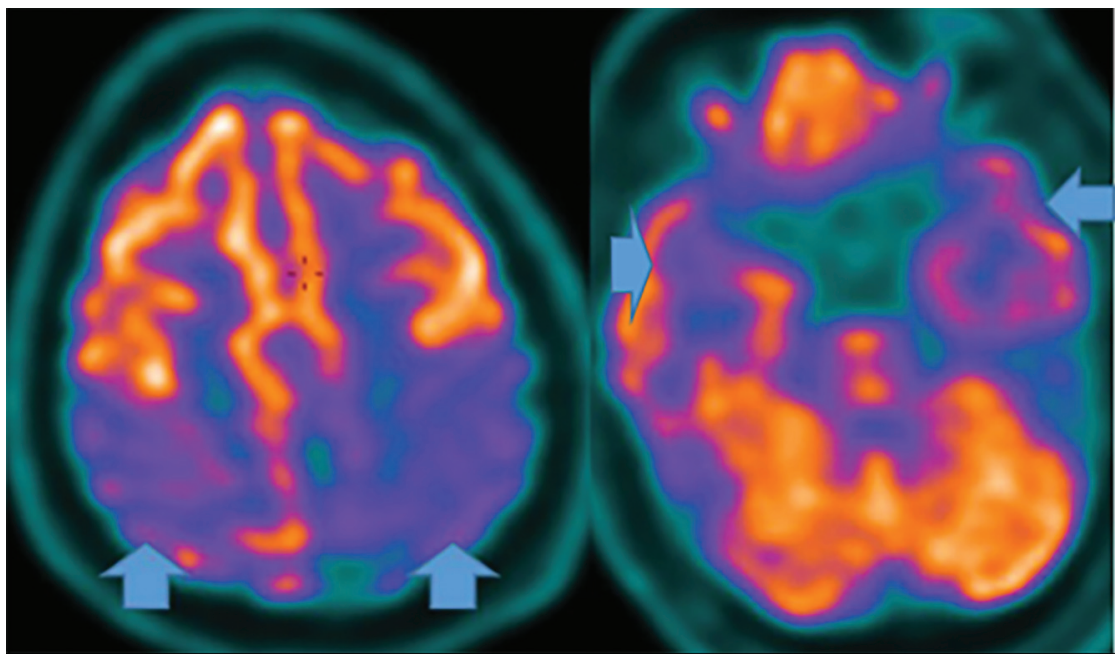

FIG 1. FDG-PET in a patient with $A D$ demonstrates decreased bilateral parietal and temporal uptake (arrows). FDG uptake in the occipital lobe is preserved (not shown). The degree of abnormalities correlates with symptoms.
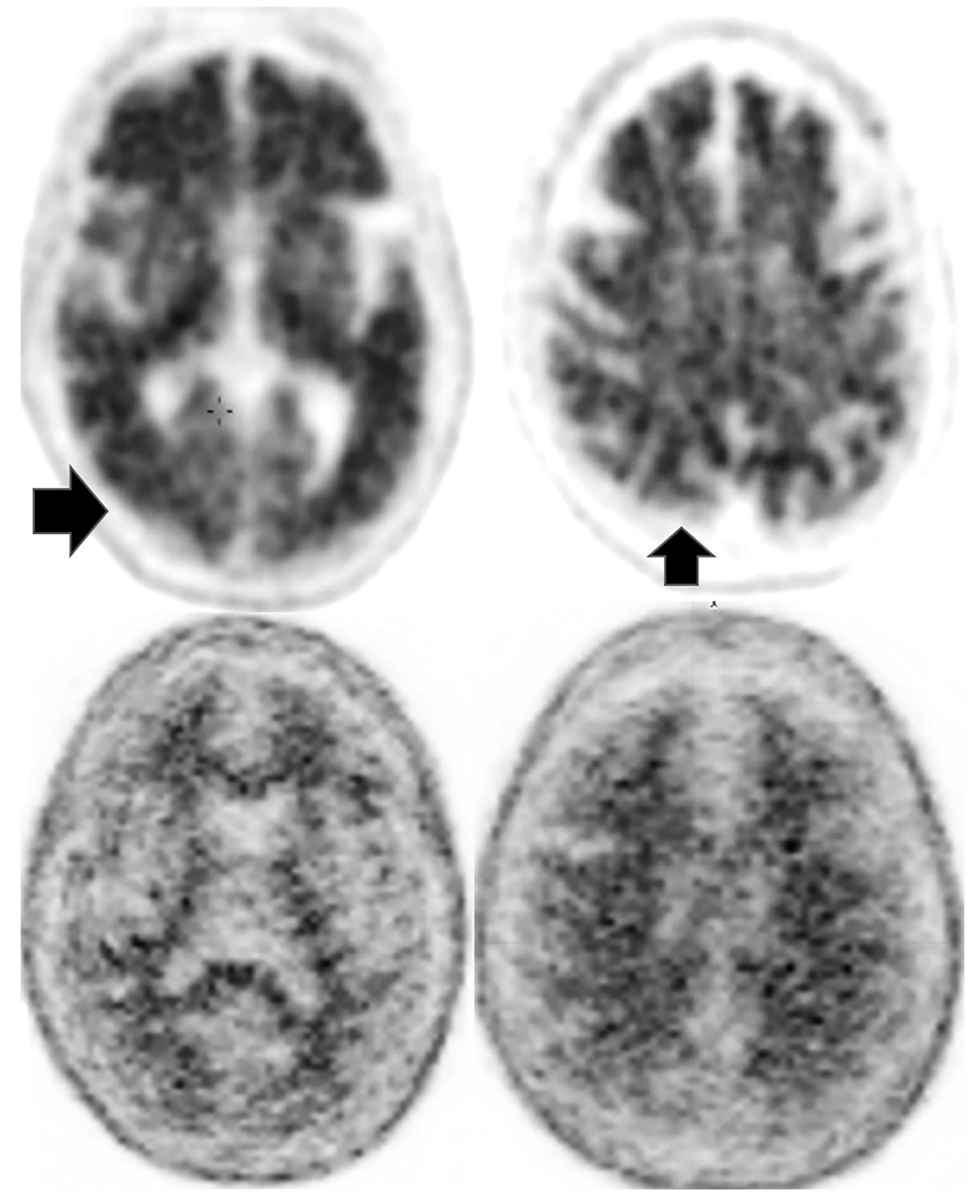

FIG 2. Upper row: Abnormal florbetapir PET (arrows) shows diffuse cortical uptake with loss of GM-WM differentiation, indicating a high amyloid plaque burden. Lower row: A 65-year-old woman with $\mathrm{MCl}$. Florbetapir scan demonstrates normal WM uptake without accumulation in the cortical gray matter, indicating no amyloid plaque. This finding effectively rules out AD (lower images courtesy of Dr Olga James, Duke University).
Two AD forms exist, early (younger than 65 years of age, which is less common and associated with autosomal dominant Presenilin genes 1 and 2) and late-onset (older than 65 years of age). Predisposing factors for late-onset are female sex (related to metabolic differences and medium fatty acid chains), the APOE4 variant (a fat metabolism protein associated with increased amyloid deposition 1 decade before diagnosis; heterozygotes [ $3 \times$ risk]; homozygotes [15× risk]), and FDG-PET uptake reductions when asymptomatic. ${ }^{4,8}$ Trauma is also associated with in-creased $\tau$ and amyloid deposition and microhemorrhages (MHs). ${ }^{3,49}$ Tau formation spreads confluently via neurons and glia and neural networks in a prionlike manner, correlating with atrophy. $4,6,7,10,11$

MR imaging demonstrates precuneus, parietal, hippocampal, entorhinal cortex, and temporal atrophy, with frontal lobe involvement in advanced cases. FDG-PET demonstrates decreased temporoparietal uptake (sensitivity $=80 \%-93 \%$ and specificity $=$ $60 \%-76 \%)$, ${ }^{3,11}$ with possible decreased inferior parietal, frontal, lateral temporal, and precuneus uptake mirroring atrophy on MR imaging. ${ }^{12,13}$ Particularly specific PET findings include posterior cingulate involvement with occipital sparing (Fig 1). ${ }^{13}$ However, similar hypometabolism is seen in $\mathrm{PD}$, bilateral parietal subdural hematomas, radiation, or vascular disease. ${ }^{8}$ Opinions vary with regard to FDG-PET use for conversion of mild cognitive impairment (MCI) to $\mathrm{AD}$ (sensitivity $=97 \%$ and specificity $=50 \%-76 \%),{ }^{3,13-15}$ while scans with negative findings indicating progression to $\mathrm{AD}$ are unlikely for 3 years. ${ }^{3}$

Amyloid deposition is associated with FDG-PET decline and precedes $\tau$ changes, which, in turn, precede abnormal glucose metabolism, all of which precede clinical symptomatology., Several tracers help visualize amyloid. Pittsburgh compound B ( ${ }^{11} \mathrm{C}-\mathrm{P}, 20-\mathrm{mi}-$ nute half-life) is logistically difficult and, hence, never reached commercial use. ${ }^{16}$ Longer half-life commercially available ${ }^{18} \mathrm{~F}$ tracers are the following: florbetapir (Amyvid), florbetaben 

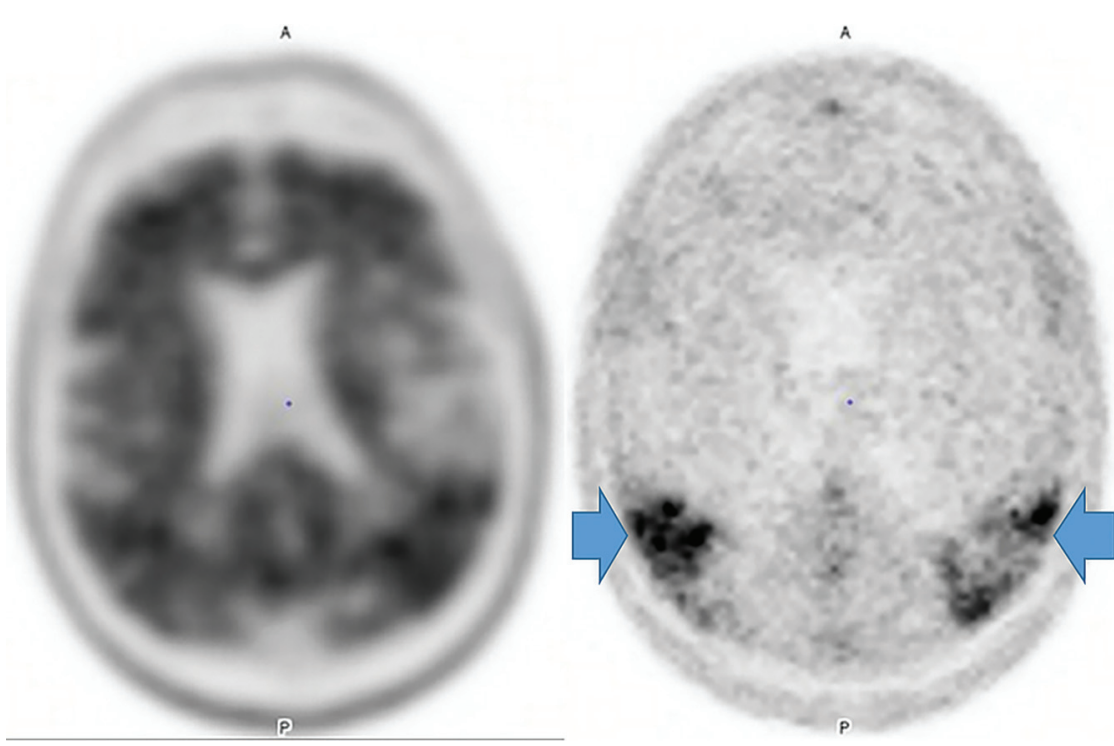

FIG 3. Increased amyloid plaque burden in the posterior parietal and frontal lobes on florbetapir PET (left) with corresponding tracer uptake in the parietal lobes on tau PET images (right, arrows). Note that the $\tau$ tracer more clearly localizes to sites of neuronal damage. The pattern is most consistent with AD (images courtesy of Dr James Burke, Duke University).
MCI intermediate between patients with $\mathrm{AD}$ and controls. ${ }^{14}$ Pooled (sensitivity and specificity) values of multiple methods of $\mathrm{AD}$ diagnosis versus controls are the following: MR imaging (visual inspection, 83/89), SPECT (80/ 85), FDG-PET (90-94/73-89), CSF amyloid- $\beta$ (80/82), CSF T- $\tau$ (82/90) and $\mathrm{p}-\tau$ (80/83), and ${ }^{18} \mathrm{~F}$ amyloid- $\beta$ (90-92/84-100). ${ }^{3,17}$ This finding explains the poor diagnostic capability with 1 test and the need for improved methods of $\mathrm{AD}$ diagnosis.

Amyloid- $\beta$ demonstrates higher negative-than-positive predictive values because $25 \%$ of postmortem examinations of cognitively healthy individuals and $21 \%$ of cognitively healthy patients have deposition; however, lack of accumulation usually excludes $\mathrm{AD}$ and $50 \%$ of patients with AD can have other pathologies. $8,17,18$ Therefore, amyloid is a good exclusionary test but limited for severity

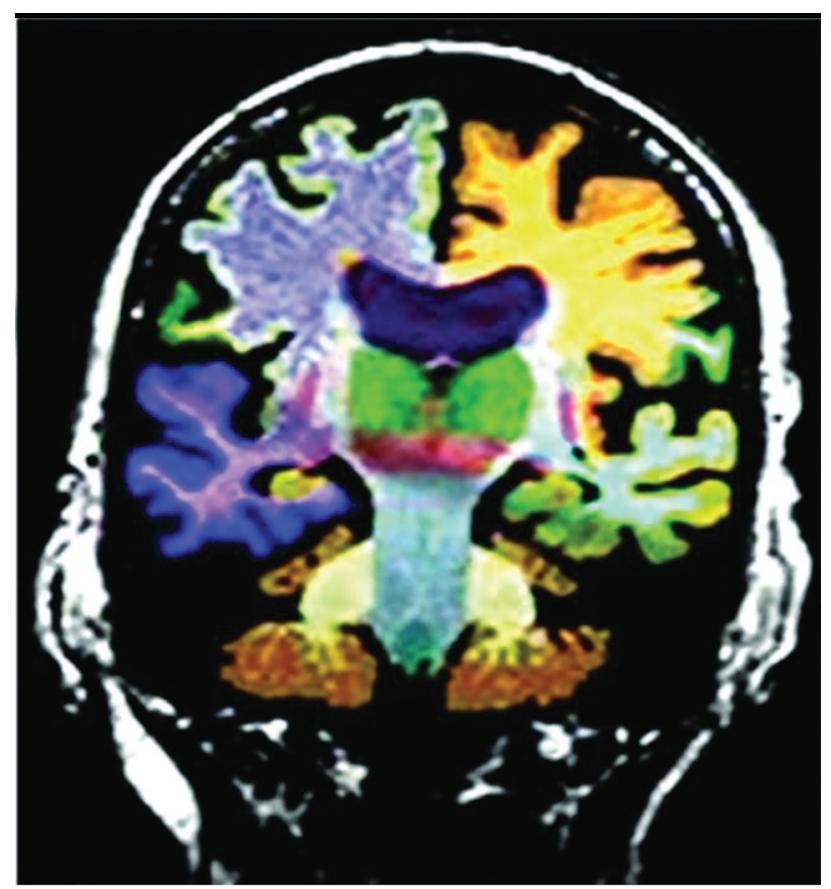

FIG 4. Commercial volumetric assessment shows lobar and deep, superficial GM differentiation by color for comparative analysis. For instance, the right frontal lobe GM is green, while the underlying WM is blue. This image was previously published in the American Journal of Neuroradiology. (Tanpitukpongse et $\mathrm{al}^{24}$ ).

(Vizamyl), and flutemetamol (Neuraceq). Recently, flortaucipir (Tavid) received FDA approval. A meta-analysis of florbetapir and florbetaben (89\%-90\% sensitivity and $87 \%-88 \%$ specificity) demonstrated no difference between agents. ${ }^{17}$ Data distinguishing AD and $\mathrm{MCI}$, however, are mixed, ${ }^{17}$ with rates of PET positive for stratification or progression depiction. Amyloid tracers in $\mathrm{AD}$ accumulate in the gray matter, while controls have primarily white matter uptake, ${ }^{19}$ producing GM-WM differentiation loss, particularly in the precuneus, posterior cingulate gyrus, and lateral-frontal and temporal lobes (Fig 2). ${ }^{20,21}$

Unlike amyloid, which does not correlate with severity, ${ }^{3,22} \tau$ uptake correlates strongly with cognitive impairment and dementia severity. ${ }^{3,22}$ Tau, particularly outside the medial temporal lobe is suspicious for $\mathrm{AD}$, even in cases negative for amyloid (Fig 3). ${ }^{23}$ However, FTD, PD, PSP, CBD, traumatic encephalopathy, and Down syndrome also accumulate $\tau .^{3,22}$ Tau, unfortunately, has concentrations 5-20 times lower than amyloid, with amygdala and striatum off-target binding. ${ }^{22}$

$\mathrm{AD} \mathrm{MR}$ imaging structural assessment reveals hippocampal (26\%-27\%), entorhinal (38\%-40\%), and thalamic and caudate volume loss (due to multinetwork connections), which is asymptomatic and precedes hippocampal loss and cortical atrophy. 3,20,24 This feature is accompanied by increased DTI diffusivity. ${ }^{3,20,24}$ Volume loss of hippocampal regions with both NeuroQuant (https://www. cortechs.ai/products/neuroquant) and Neuroreader (https:// brainreader.net/) is the single best prediction of $\mathrm{AD}$ from $\mathrm{MCI}$ at 3year follow-up compared with other regions (Fig 4). ${ }^{24} \mathrm{~T} 2 \mathrm{WM}$ hyperintensity burden and the Fazekas score (particularly perivascular) show promise, correlating with Montreal Cognitive Assessment scores and amyloid burden, while negatively correlating with FDGPET uptake. ${ }^{25-27}$ T2 abnormalities occur 20 years before disease expression, particularly in late-myelinating regions secondary to neurodegeneration and poor oligodendrocyte repair. ${ }^{28}$ Additionally, iron SWI measurement, rsfMRI/task-based fMRI, arterial spinlabeling, MR spectroscopy (lower NAA and higher mIns), and DTI (reduced hippocampal, thalamic, and caudate anisotropy) are under investigation. ${ }^{4,20,25,27}$ In summary, WM burden predicts $\mathrm{AD}$ and cognitive decline and correlates with amyloid and $\tau$ CSF levels and 


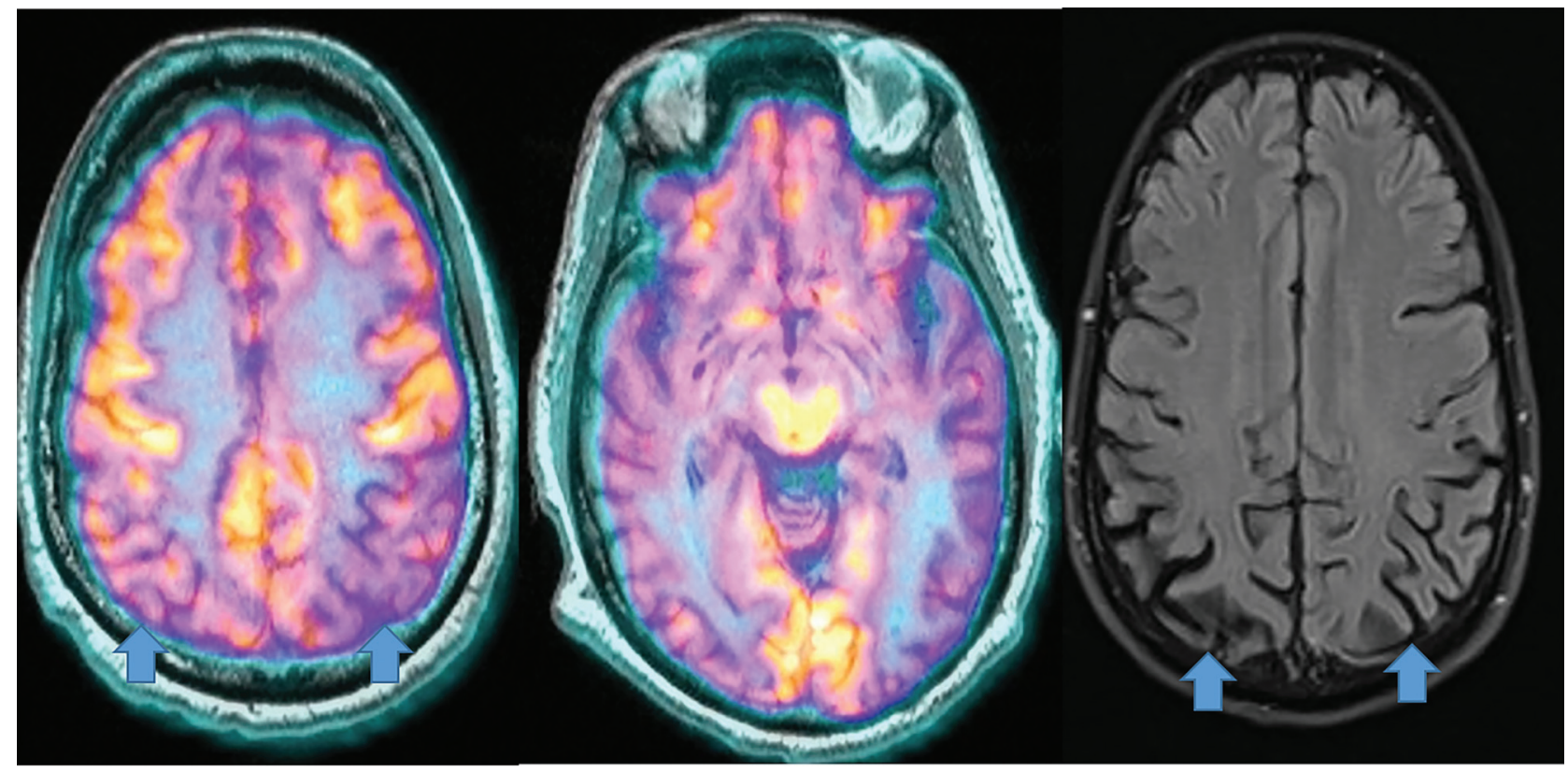

FIG 5. Posterior cortical atrophy ( $A D$ variant) demonstrates preserved frontal and caudate but decreased lateral occipital and parietotemporal uptake (left, 2 color images), while an axial FLAIR (black and white), right MRI image demonstrates focal posterior parietal (arrows) and parietooccipital atrophy (arrows). This patient demonstrated temporal sparing (not shown).

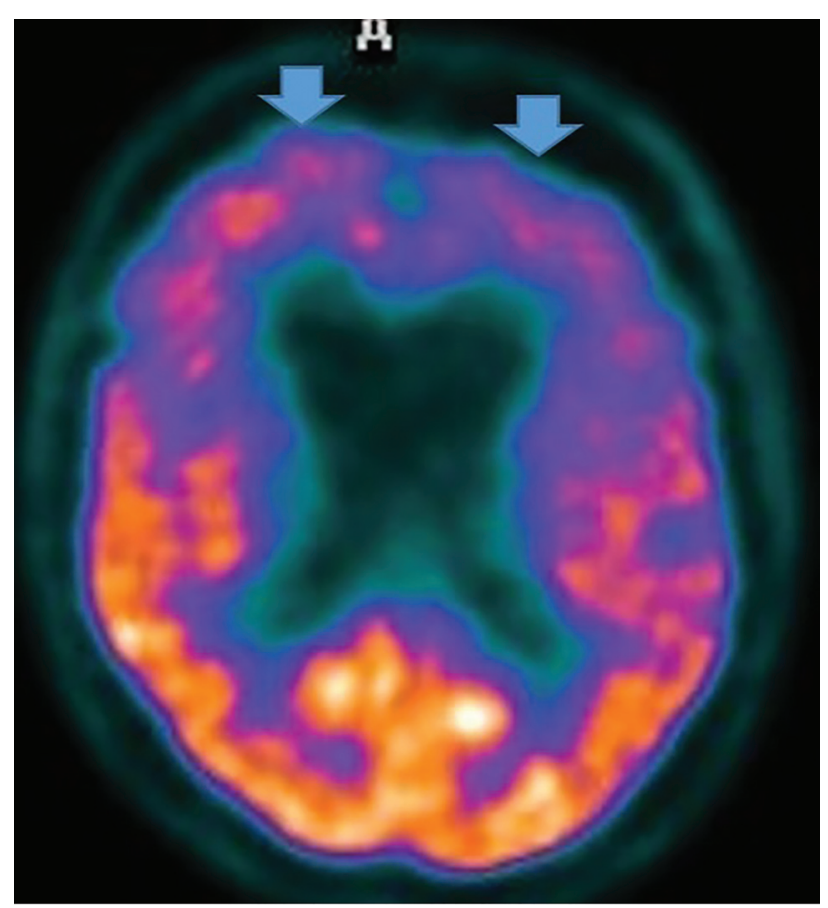

FIG 6. FTD. Frontal and behavioral variant demonstrates reduced bifrontal FDG-PET uptake (arrows). Also note the enlargement of the frontal horns of the lateral ventricles, a common finding.

decreased perfusion and abnormal DTI networks before atrophy or abnormal findings on FDG-PET. ${ }^{28}$

A new possible surrogate marker is iron (Fe), because amyloid- $\beta$ causes oliogodendrocyte toxicity, preventing myelin repair. $^{28,29}$ Subsequently, Fe released during myelin breakdown creates phosphorylated- $\tau / \tau .^{29,30}$ Additionally, rsfMRI and task- based MR imaging show potential, demonstrating impaired default mode network connectivity correlating with amyloid- $\beta$ deposition, ${ }^{4,27,31,32}$ and frontoparietal and visual network hypoactivation in MCI relative to controls as well as visual, default, limbic, and dorsal and ventral attention network hypoactivation in $\mathrm{AD}$ relative to controls. ${ }^{32}$ Dynamic susceptibility contrast-enhanced and arterial spin-labeling MR imaging assessment is another focus of MR imaging research. ${ }^{3,27}$ New nuclear medicine tracers targeting dopamine and serotonin/cholinergic/GABAergic systems and microglial neuroinflammation (translocator protein agents correlate with amyloid) and astrocyte agents are under investigation. ${ }^{3,8,27,33}$ Unfortunately, translocator protein agents exhibit 3 genetic-related nucleotide polymorphisms affecting uptake, poor resolution, and more activity later rather than earlier in the disease process. ${ }^{3,8,27,33}$ $\left[{ }^{11} \mathrm{C}\right]$-deuterium-L-deprenyl $\left[{ }^{11} \mathrm{C}\right]-\mathrm{DED}$ and $\left[{ }^{11} \mathrm{C}\right]$-deprenyl-D2 are less well-studied. ${ }^{3,8,25,27,33}$ Hopefully, the ongoing Alzheimer's Disease Neuroimaging Initiative 3 trial will yield answers with regard to these new methods.

Posterior Cortical Atrophy. Posterior cortical atrophy (an $\mathrm{AD}$ variant) presents with declining visual association skills affecting the lateral occipital lobes (unlike classic $\mathrm{AD}$ ), while preserving the frontal lobes and caudate (unlike LBD), often with subtle MR imaging findings (Fig 5). ${ }^{34}$

\section{Frontotemporal Dementia}

FTD demonstrates 3 variants: behavioral, semantic, and nonfluent agrammatic aphasia. Related syndromes include FTD motor neuron disease, PSP, and CBD, discussed separately. FTD neuropathology is variable, with $\tau$, TAR DNA-binding protein 43/FET proteins, and sometimes amyloid (Online Supplemental Data). ${ }^{8,31,35}$

Behavioral variant FTD (the most common variant) shows progressive behavior and cognition deterioration; perseverative, 


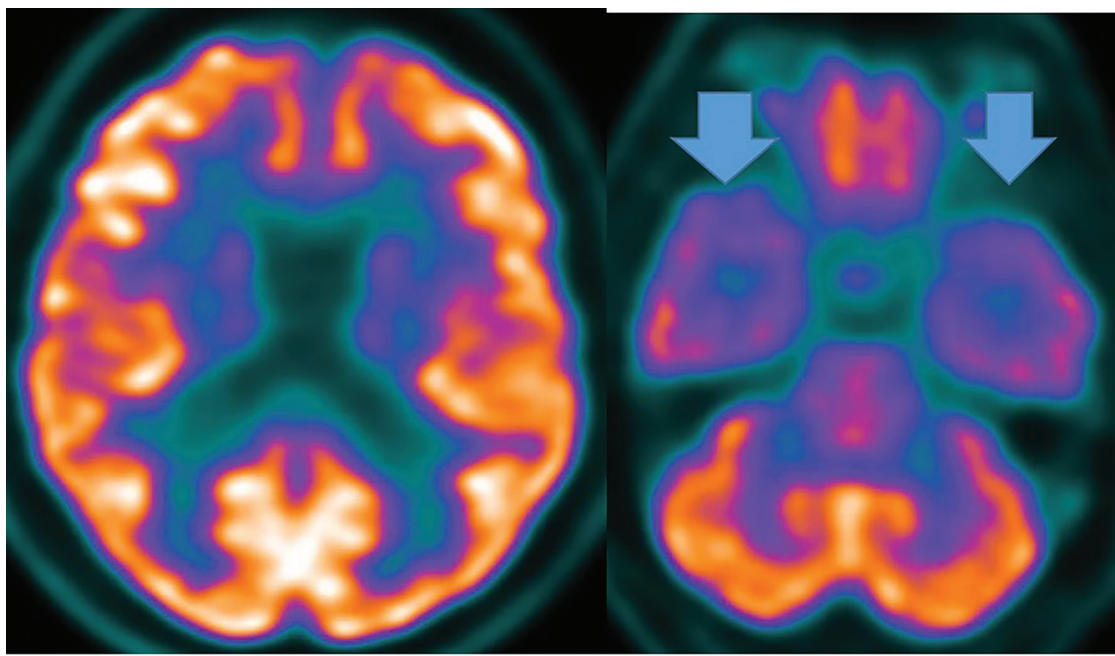

FIG 7. FTD. Semantic and temporal variant demonstrates significant reduced bitemporal uptake (arrows) without reduced frontal FDG-PET uptake as seen in Fig 6.

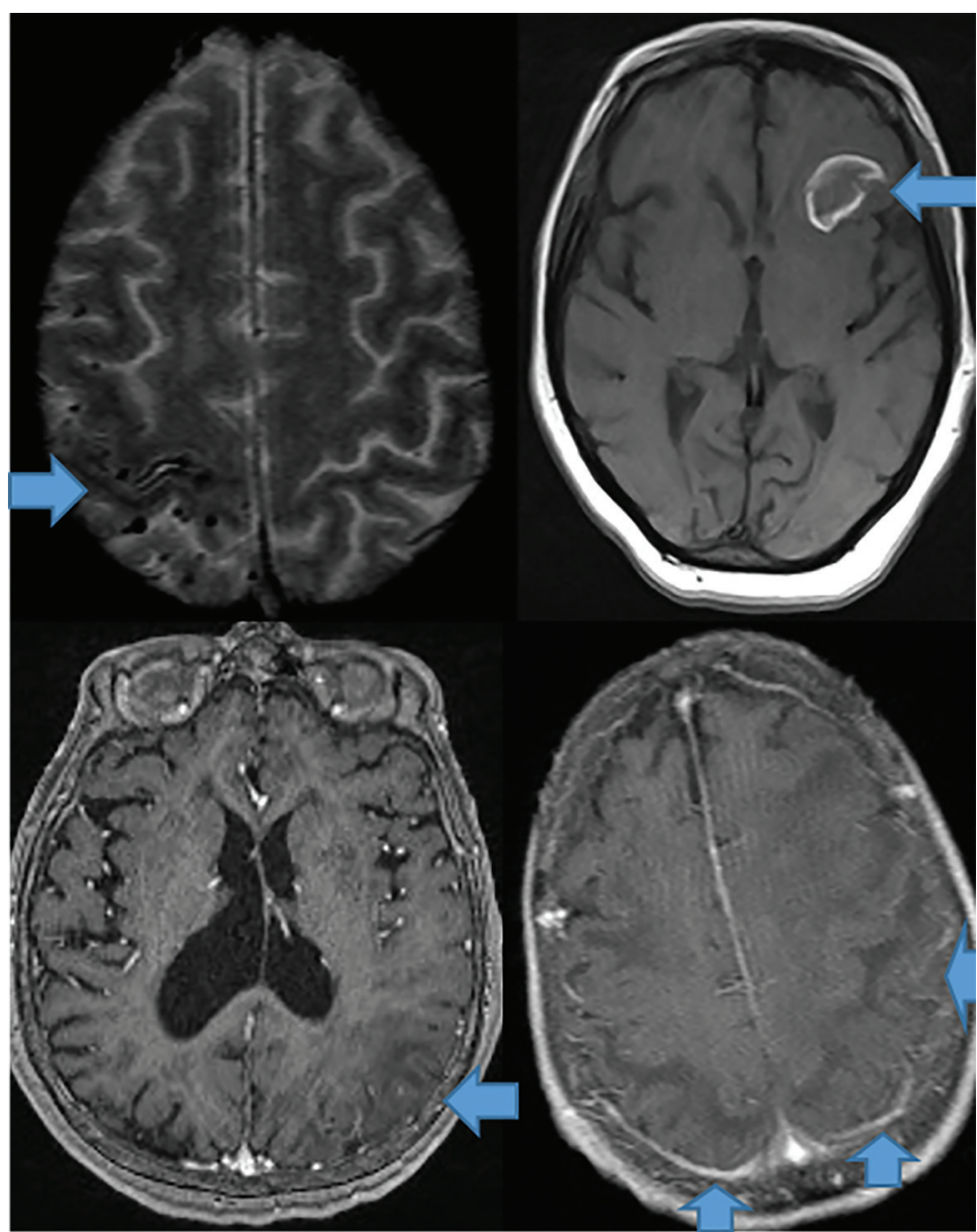

FIG 8. CAA presents as multiple forms. In the classic CAA form (top left, axial T2), subarachnoid hemorrhage is common as seen at the arrow, on susceptibility weighted imaging with clustered right fronto-parietal MHs in the adjacent brain parenchyma. Large frontal parenchymal hemorrhages can also be seen in classic CAA (top right image, axial T). The inflammatory cerebral amyloidosis type will demonstrate edema as seen in this case with left parietal edema/mass effect (bottom left, axial $+\mathrm{C} T$ at arrow). While the Amyloid- $\beta$ related angitis variant commonly demonstrates dural/ leptomeningeal enhancement seen posteriorly (arrows), (bottom left image, axial $+\mathrm{C} \Pi$ at arrow). Note the lack of mass effect in the Amyloid- $\beta$ angitis variant. stereotyped, compulsive and ritualistic behavior; and hyperorality and dietary changes, but it spares memory and visuospatial functions. MR imaging demonstrates frontal and anterior-temporal atrophy, while FDG-PET reveals decreased cortical medial-frontal, orbital-frontal, anterior cingulate, and frontoinsular uptake, ${ }^{35}$ with expected differences between frontal, behavioral (Fig 6), temporal, and semantic (Fig 7) variants. ${ }^{36}$ Anterior cingulate, temporal, caudate, and thalamic involvement is a key difference from $\mathrm{AD}$ and correlates with disease progression. ${ }^{33,37,38}$ FTD typically does not show amyloid uptake, but $\tau$ uptake has been seen. ${ }^{33}$

Patients with the semantic variant demonstrate impaired confrontation naming, single-word comprehension, object knowledge, and surface dyslexia and dysgraphia, sparing speech production. MR imaging reveals anterior-temporal atrophy, correlating with FDGPET and SPECT hypoperfusion and hypometabolism. ${ }^{35}$ Finally, patients with the nonfluent and agrammatic variant lack grammar and speech apraxia but have impaired complex-sentence comprehension, sparing single-word comprehension/object knowledge. MR imaging demonstrates left posterior, frontoinsular atrophy, while FDG-PET and SPECT depict hypoperfusion and hypometabolism in the same region. ${ }^{35}$

Newer MR imaging techniques demonstrate thalamic atrophy ${ }^{39}$ and DTI tract differences between the behavioral variant (uncinate fasciculus, genu, and cingulum) and Primary Progressive Aphasia, while $\mathrm{AD}$ shows increased fractional isotropy and mean diffusivity. ${ }^{40}$ Behavioral variant subtypes demonstrate regional prefrontal-cortical, anterior-temporal, insular, anterior cingulate, and striatum volume loss. ${ }^{40}$ Meanwhile, rsfMRI reveals re-duced salience network connectivity in the behavioral variant, abnormal executive dorsal attention-control and auditory networks, and increased default mode network connectivity, positively correlating with symptom severity. $^{31}$ Additionally, $\mathrm{Fe}$ deposition assessment differentiates those with the behavioral variant from controls and those with the Primary Progressive Aphasia variant from those with the behavioral variant. $^{41}$ 


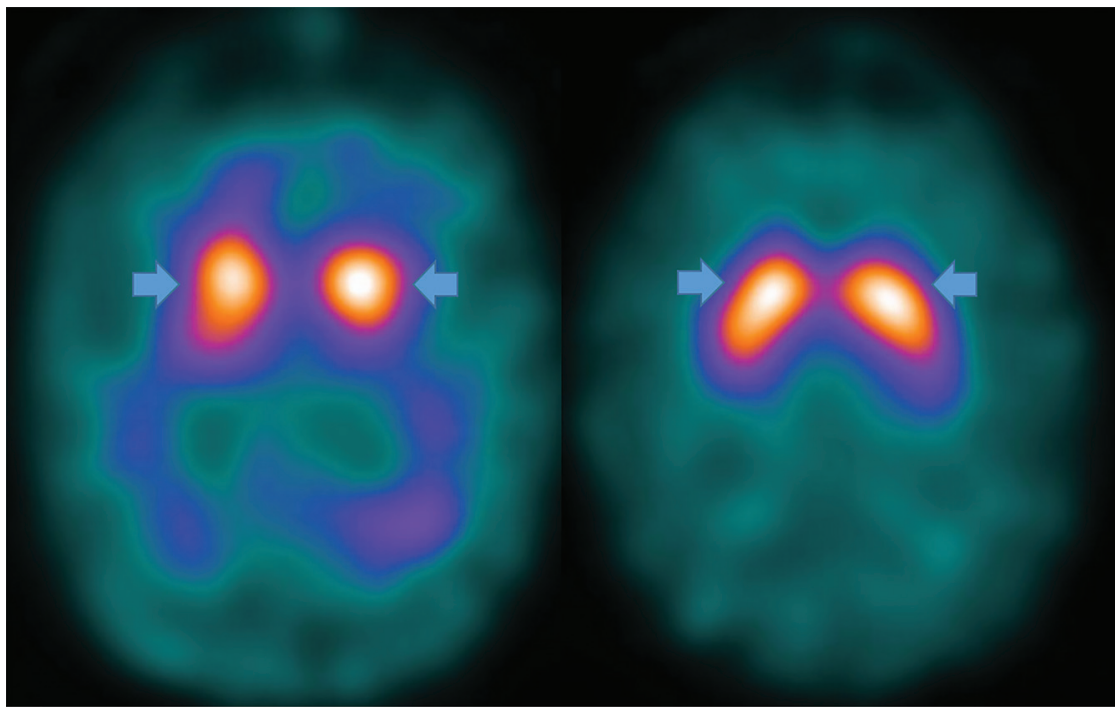

FIG 9. PD decreased putaminal > caudate head uptake results in the classic change from a "comma" (right image arrows) to a "period" (left image arrows) appearance. Note abnormal (left) and normal (right) findings on DaTSCANs.

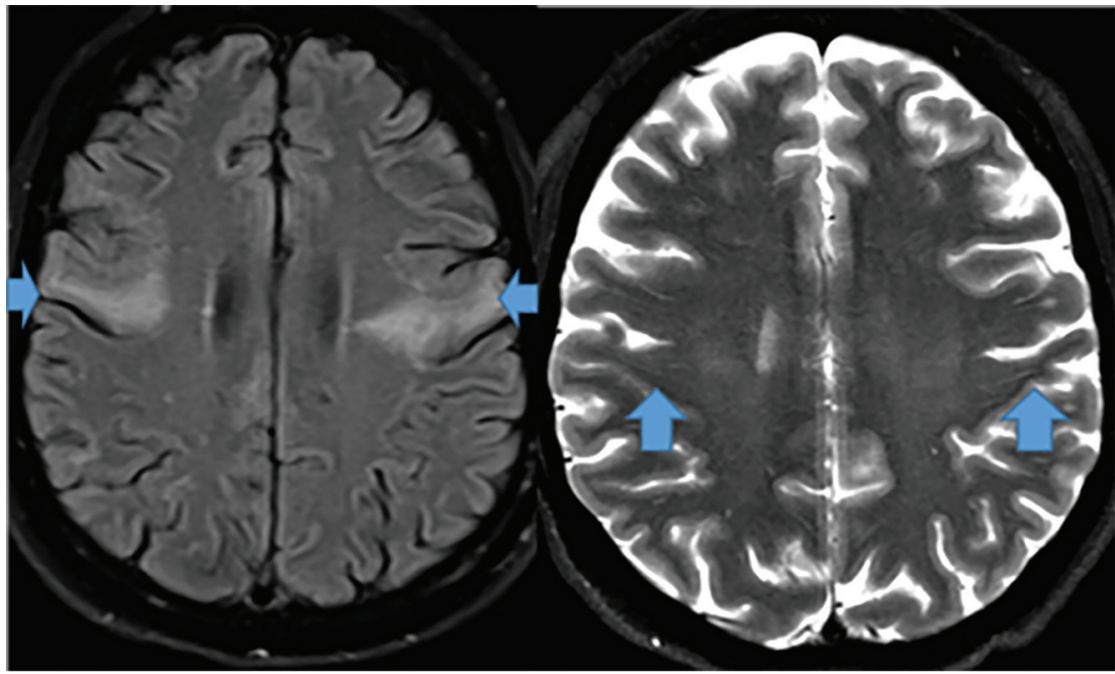

FIG 10. Amyotrophic lateral sclerosis demonstrates significant bilateral precentral sulcus increased corticospinal tract FLAIR signal (arrows, axial image, left) and decreased axial T2 precentral sulcus signal, "motor band sign" (right, arrows) on MR imaging.

\section{Cerebral Amyloid Angiopathy}

CAA dementia occurs in elderly normotensive individuals. Pathophysiologically, amyloid deposits in cortical and meningeal arterioles and capillary walls. ${ }^{42}$ Patients present with basal gangliasparing subcortical lobar MHs. There are 3 forms: classic, inflammatory, and amyloid-related angiitis. ${ }^{42,43}$ Patients with classic amyloid can demonstrate superficial siderosis, subarachnoid hemorrhage, and multiple MHs with posterior-predisposition T2 FLAIR changes (Fig 8) due to higher lipoprotein concentration. ${ }^{44}$ Inflammatory amyloid (poorest prognosis) exhibits clustered $\mathrm{MHs}$, minimal enhancement, and significant mass effect (Fig 8). Amyloid- $\beta$-related angiitis, however, lacks mass effect but often has meningeal enhancement (Fig 8). Cerebral MHs correlate with neurologic deficits. ${ }^{45,46}$
Given the presence of amyloid, amyloid PET findings are often positive, but being negative excludes $\mathrm{CAA}^{42,45}$ (sensitivity $=77 \%-92 \%$ and specificity $=66 \%-88 \%$ versus controls); ${ }^{46}$ however, the more common AD may coexist. ${ }^{42}$ Hence, some authors propose an occipital-to-global amyloid ratio to differentiate CAA with regard to $\mathrm{AD}$ ( $\mathrm{AD}$ spares the occipital lobes). ${ }^{46}$ Definitive FDG-PET CAA diagnosis awaits future research.

\section{Parkinson Disease and Related Syndromes}

PD presents with resting tremor and cognitive decline secondary to decreased pigmented, substantia nigra/pars compacta dopaminergic neurons, and $\alpha$-synuclein protein intraneuronal Lewy body inclusions. ${ }^{47} \mathrm{~T} 2 \mathrm{MR}$ imaging shows an absent substantia nigra swallowtail sign, indistinctness, and Fe deposition. ${ }^{48}$

FDG-PET differentiates Parkinson disease from related dementias via decreased basal ganglia uptake, ${ }^{49}$ while ${ }^{18} \mathrm{~F}$ fluorodopa demonstrates decreased striatal uptake. ${ }^{50}$ Parkinson disease appears similar to AD on FDGPET, but with greater visual cortex involvement and relative medial-temporal cortex preservation. ${ }^{50}$ Amyloid and (less frequently) $\tau$ imaging is positive. ${ }^{51}$ The principal nuclear medicine study used to evaluate PD is ${ }^{123} \mathrm{I}$ ioflupane/DaTSCAN (GE Healthcare) SPECT (Fig 9) showing decreased putamen and caudate uptake. ${ }^{51}$

There are 3 PD variants: PSP, amyotrophic lateral sclerosis, and MSA. PSP (possibly an FTD variant) demonstrates anterior-midbrain convexity loss on sagittal views (hummingbird sign) with interpeduncular cistern widening, and patients demonstrate upward gaze paralysis. ${ }^{52}$ Amyotrophic lateral sclerosis demonstrates motor strip and corticospinal tract hyperintense T2 FLAIR signal secondary to Fe deposition (Fig 10). MSA presents with autonomic failure and a T2 brain stem "hot cross buns" configuration (Fig 11)..$^{52}$

Parkinsonian syndromes reveal decreased FDG-PET uptake; PSP in the medial frontal, premotor, prefrontal, brain stem, and thalamic regions; and MSA in the putamen, cerebellum, and brain stem regions (Fig 12). ${ }^{33,47,49}$ Finally, CBD demonstrates asymmetric decreased parietal and primary sensorimotor cortex, medial and lateral premotor, striatum, and thalamic uptake contralateral to clinical findings. ${ }^{33} \mathrm{PD}$ may show cortical and striatal amyloid uptake. ${ }^{33}$ Tau tracers may accumulate in the inferior-temporal cortex in PD, while they are in the frontal-temporal, posterior-cingulate, subthalamic, 
midbrain, and cerebellar WM in PSP. In CBD, Tau uptake is seen in the frontal, and parietal cortex (not seen in MSA). ${ }^{33,52}$

With MR imaging, increased substantia nigra quantitative SWI suggests biomarker potential, as does prefrontal cortex and putamen $\mathrm{Fe}$, which correlates with lower cognitive function. ${ }^{30,52,53}$ Likewise, rsfMRI default mode network assessment reveals altered striatum, motor, cerebellar, and basal ganglia connectivity, though disease heterogeneity inhibits biomarker progress. ${ }^{31,32}$

\section{Lewy Body Dementia (DLB)}

DLB $\alpha$-synuclein pathology represents $15 \%$ of neurodegenerative disease, and like Parkinson disease, it sometimes exhibits amyloid and $\tau$ pathology. ${ }^{54}$ Indicative criteria (diagnostic if present) include radiologic biomarkers for DLB-reduced dopamine transport on DaTSCAN SPECT or fluorodopa PET, or low
Metaiodobenzylguanidine (MIBG) cardiac uptake. Supportive criteria are relative $\mathrm{CT} / \mathrm{MR}$ imaging medial temporal lobe preservation and low uptake on SPECT/PET perfusion and metabolism (FDG) imaging, with reduced generalized uptake, reduced occipital uptake, and cingulate preservation. ${ }^{55}$

Regardless, FDG-PET demonstrates temporoparietal involvement. Unlike $\mathrm{AD}$, the occipital lobes are not spared. ${ }^{56}$ The most sensitive PET finding is lateral-occipital cortex involvement (88\%), while the most specific finding is posterior cingulate preservation (Fig 13). ${ }^{33}$ DaTSCAN SPECT (80\% accurate for AD differetiation) shows decreased putamen $>$ caudate uptake. ${ }^{54}{ }^{123} \mathrm{I}$ Metaiodobenzylguanidine (MIBG) (catecholamine-receptor tracer) assessment shows decreased cardiac activity secondary to postganglionic-sympathetic cardiac innervation degeneration. ${ }^{54}$ Tau tracers show posterior-temporoparietal, occipital-cortical, and precuneus uptake. $^{29}$ On MR imaging, medial-temporal preservation (regarding $\mathrm{AD}$ ) is supportive but nonspecific, as is occipital hypometabolism and preserved posterior and midcingulate metabolism on FDG-PET (decreased posterior cingulate uptake is $\mathrm{AD}$-specific).

Novel rsfMRI demonstrates widespread connectivity alterations without a current extent and disease localization consensus. ${ }^{31}$ Recently, the swallow tail sign was described in DLB. ${ }^{48}$

\section{Huntington Disease}

Huntington disease is a rare autosomal dominant disease demonstrating increased chromosome 4pCAG-trinucleotide repeats, increased gamma-aminobutyric acid, and neuronal loss. The more common adult form presents

FIG 11. MSA demonstrates a pontine
nal atrophy (right, arrows, axial T2).

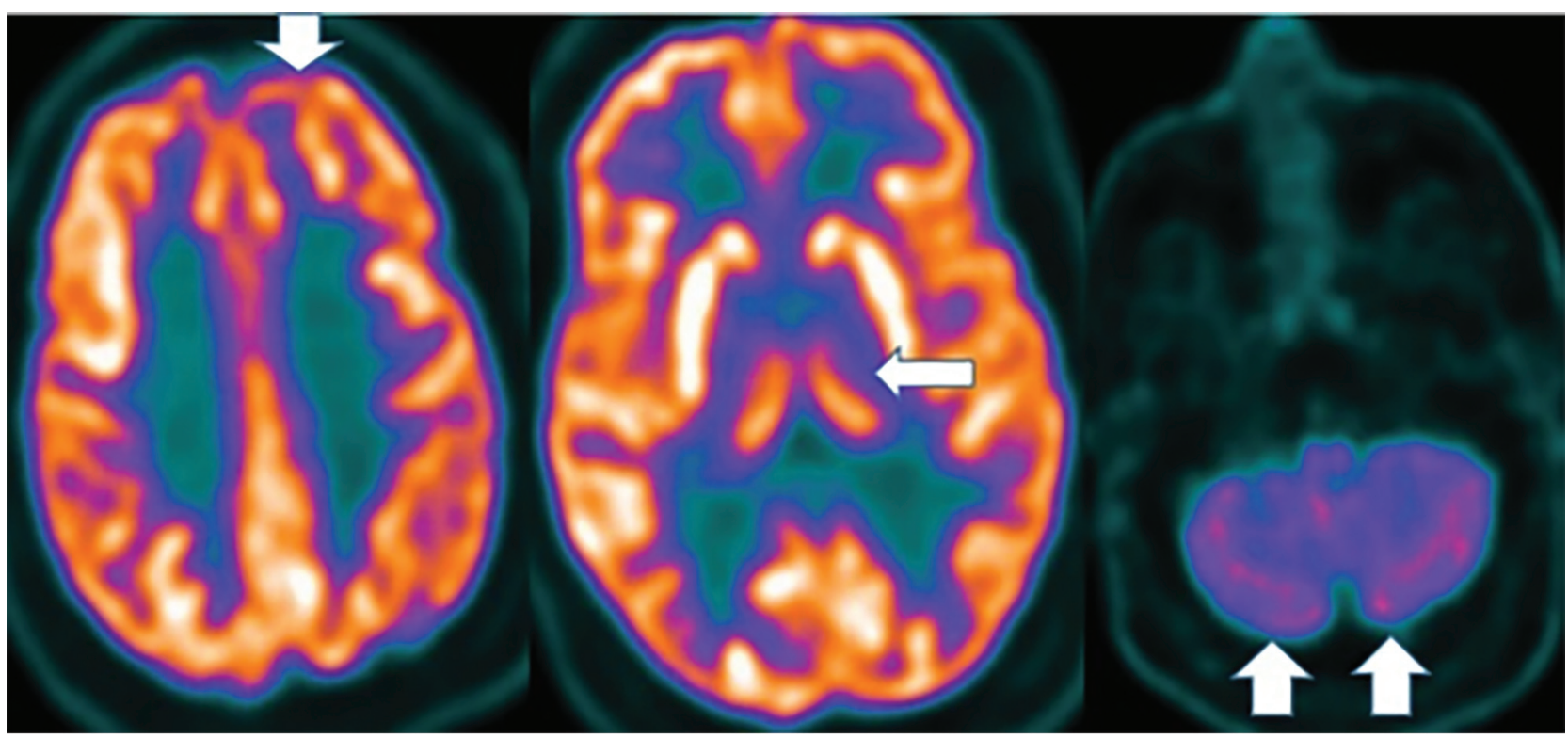

FIG 12. MSA-Cerebellar FDG-PET reveals decreased medial frontal (left), thalamic (middle), and cerebellar (right) uptake (arrows). 


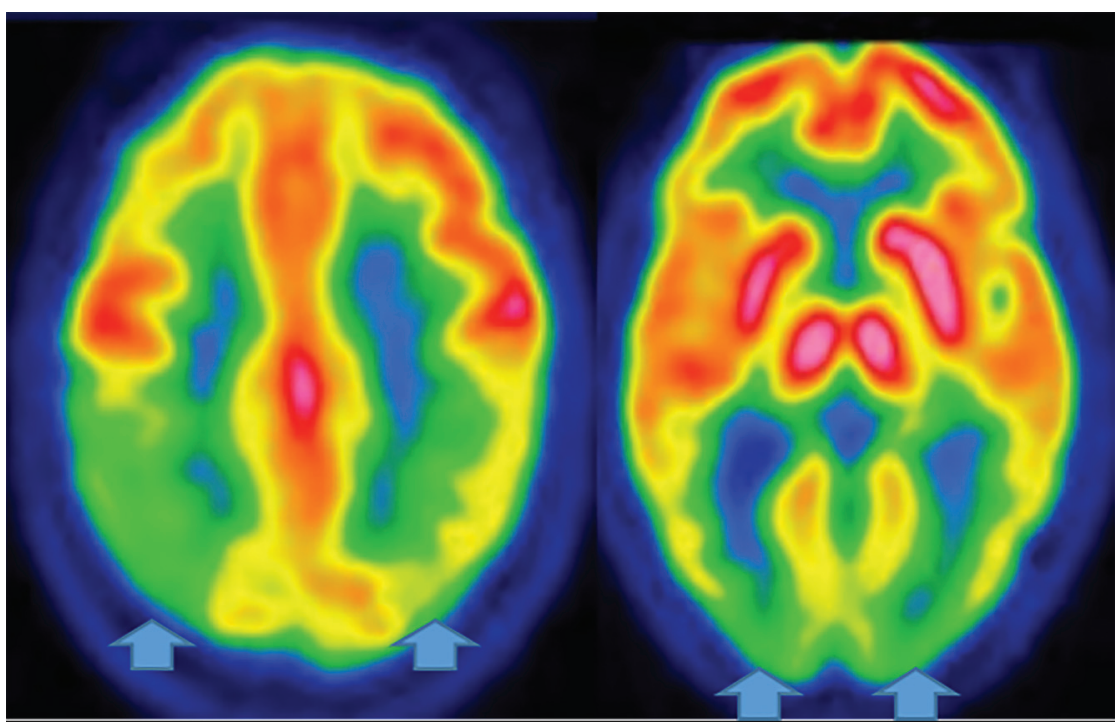

FIG 13. DLB. FDG-PET reveals reduced posterior parietal and occipital activity (arrows), but preserved posterior cingulate uptake (images courtesy Dr. Daniel Silverman, University of California, Los Angeles).

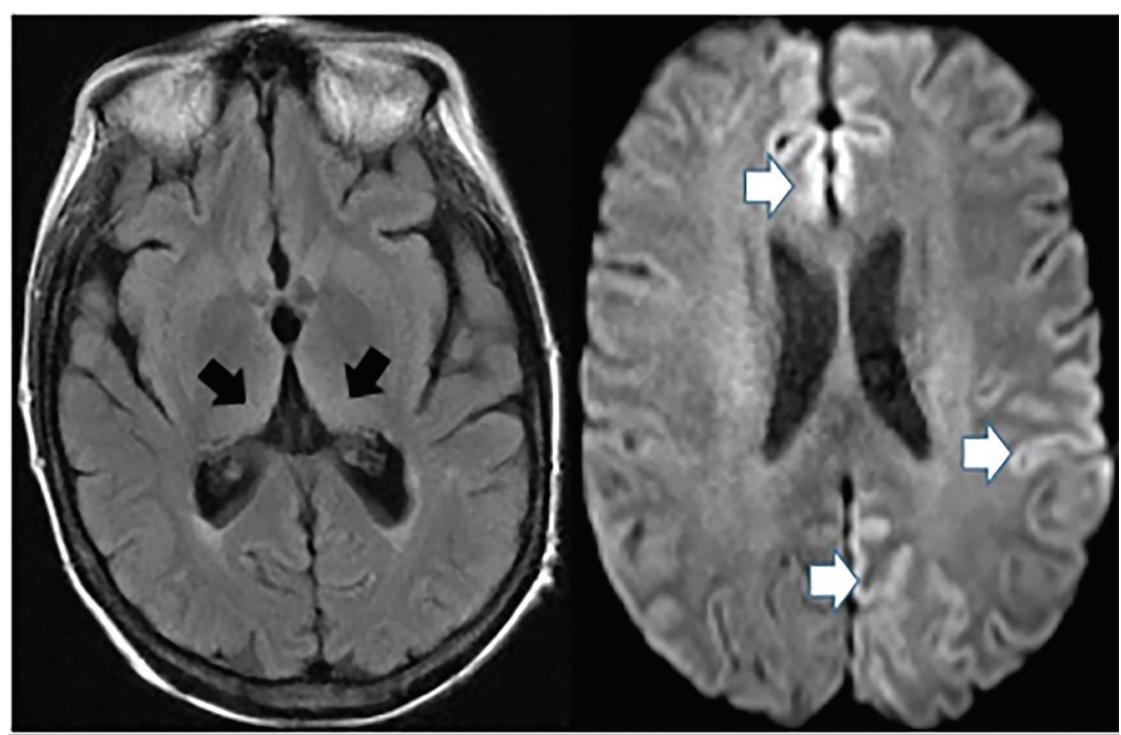

FIG 14. Creutzfeldt-Jakob disease demonstrates hockey stick configuration (black arrows), medial thalamic increased FLAIR (left axial image) as well as medial frontal, left parietal and occipital cortical increased signal (white arrows) (cortical ribbon sign, right axial image).

\section{Vascular Dementia}

While strokes are more common than any other neurodegenerative disease, they rarely present in FDG-PET. MR imaging and PET reveal a sharp demarcation of involved arterial territories. If the frontal or internal capsule is affected, there may be loss of uptake and atrophy in the contralateral cerebellum (crossed-cerebellar diaschisis). ${ }^{34}$

\section{Creutzfeldt-Jakob Disease}

Creutzfeldt-Jakob disease causes rapid cognitive decline from altered prion protein accumulation, producing neurotoxicity and cortical/subcortical spongiform necrosis. On MR imaging, striatum and neocortex increased T2 FLAIR (medial-thalamic hockey-stick configuration) is noted, often also affecting the cortex (Fig 14). SPECT reveals widely inconsistent perfusion variations, and FDG-PET shows cortical and basal ganglia involvement in later stages. $^{61}$

\section{CONCLUSIONS}

This article addresses clinical, pathologic, MR imaging, and PET findings, including new techniques, to educate the readership. Major differentiating MR imaging and PET and pathologic facts are summarized (Online Supplemental Data) to assist with greater understanding. Complicating imaging diagnosis are concomitant pathologies with similar abnormal metabolites. ${ }^{3,5}$ Hence, MR imaging techniques like atrophy analysis; MR spectroscopy; DTI; $;^{4,20,24}$ quantitative SWI Fe analysis in $\mathrm{AD}, \mathrm{FTD}$, $\mathrm{PD}$, and $\mathrm{LBD} ;^{2,9,30,41,48,53,54}$ and taskbased/rsfMRI in AD, LBD, FTD, and $\mathrm{PD}^{4,24,27,31,32,37,40}$ are under investigation. Currently, direct comparisons of SWI and fMRI techniques with molecu-

with chorea and dystonia, swallowing difficulty, abnormal and slow eye movements, and impaired gait and posture and balance. By the fourth-to-fifth decades, cognitive decline and word-finding difficulty and emotional lability are seen. Patients presenting at younger than 20 years of age have the rarer juvenile form. ${ }^{57}$

MR imaging demonstrates frontal horn box-shaped dilation and caudate atrophy. There are no nuclear medicine diagnostic findings, though FDG-PET demonstrates striatal and cortical hypometabolism with increased thalamus and occipital and cerebellar uptake. ${ }^{57-60}$ rsfMRI exhibits visual, motor, and basal ganglia network abnormalities. ${ }^{32,40}$ lar imaging and clinical markers are lacking, possibly slowing diagnosis and understanding of disease progression. Also lacking are multitracer comparative studies, possibly cost-related and due to poor reimbursement by payors. However, newer techniques and radiotracers ( $\tau$ [PI-2620], a cholinergic, dopaminergic, translocator protein) show needed great promise. Additionally, quantitative atrophy and WM burden analysis as a standard part of examinations with multifactorial analysis of molecular imaging (PET and MR imaging) ${ }^{3,24}$ and Lumbar Puncture findings like the "DuBois criteria" promise better accuracy and treatment development, both urgently needed in our aging society. ${ }^{4}$

AJNR Am J Neuroradiol 42:998-1007 Jun 2021 www.ajnr.org 


\section{ACKNOWLEDGMENTS}

We thank Olga James, James Burkek, and Daniel Silverman for contribution of images.

Disclosures: Valerie L. Jewells_UNRELATED: Payment for Development of Educational Presentations: American Osteopathic College of Radiology, Comments: I gave a lecture on this topic and received a \$250 stipend. Terence Z. WongRELATED: Consulting Fee or Honorarium: Lilly USA, LLC, Comments: In 2012, I served as a consultant to develop educational training materials for the interpretation of florbetapir scans (amyloid imaging for dementia).

\section{REFERENCES}

1. Beach TG, Monsell SE, Phillips LE, et al. Accuracy of the clinical diagnosis of Alzheimer disease at National Institute on Aging Alzheimer Disease Centers, 2005-2010. J Neuropathol Exp Neurol 2012;71:266-73 CrossRef Medline

2. Sala Frigerio C, De Strooper B. Alzheimer's disease mechanisms and emerging roads to novel therapeutics. Annu Rev Neurosci 2016;39:57-79 CrossRef Medline

3. Femminella GD, Thayanandan T, Calsolaro V, et al. Imaging and molecular mechanisms of Alzheimer's disease: a review. Int J Mol Sci 2018;19:3702 CrossRef Medline

4. Reiman EM, Jagust WJ. Brain imaging in the study of Alzheimer's disease. Neuroimage 2012;61:505-16 CrossRef Medline

5. Arnold M, Nho K, Kueider-Paisley A, et al. Sex and APOE4 genotype modify the Alzheimer's disease serum metabolome. Nat Commun 2020;11:1148 CrossRef Medline

6. Rasmussen MK, Mestre H, Nedergaard M. The glymphatic pathway in neurological disorders. Lancet Neurol 2018;17:1016-24 CrossRef Medline

7. Hay J, Johnson VE, Smith DH, et al. Chronic traumatic encephalopathy: the neuropathological legacy of traumatic brain injury. Annu Rev Pathol 2016;11:21-45 CrossRef Medline

8. Tiepolt S, Patt M, Aghakhanyan G, et al. Current radiotracers to image neurodegenerative disease. EJNMMI Radiopharm Chem 2019;4:17 CrossRef Medline

9. Yates PA, Desmond PM, Phal PM, et al. AIBL Research Group. Incidence of cerebral microbleeds in preclinical Alzheimer disease. Neurology 2014;82:1266-73 CrossRef Medline

10. Barthélemy NR, Li Y, Joseph-Mathurin N, et al. Dominantly Inherited Alzheimer Network. A soluable phosphorylated tau signature links tau, amyloid and the evolution of stages of dominantly inherited Alzheimer's disease. Nat Med 2020;26:398-407 CrossRef Medline

11. Khosravi M, Newberg A, Alavi A. Cognitive impairment and dementias. Semin Nucl Med 2018;48:498-512 CrossRef Medline

12. Ibanez V, Pietrini P, Alexander GE, et al. Regional glucose metabolic abnormalities are not the result of atrophy in Alzheimer's disease. Neurology 1998;50:1585-93 CrossRef Medline

13. Ma HR, Sheng LQ, Pan PL, et al. Cerebral glucose metabolic prediction from amnestic mild cognitive impairment to Alzheimer's dementia: a meta-analysis. Transl Neurodegener 2018;7:9 CrossRef Medline

14. Smailagic N, Lafortune L, Kelly S, et al. 18F-FDG PET for prediction of conversion to Alzheimer's disease dementia in people with mild cognitive impairment: an updated systematic review of test accuracy. J Alzheimers Dis 2018;64:1175-94 CrossRef Medline

15. Martinez G, Vernooij RW, Fuentes PP, et al. 18F-PET with florbetapir for the early diagnosis of Alzheimer's disease dementia and other dementias in people with mild cognitive impairment (MCI). Cochrane Database Syst Rev 2017;11:CD012216 CrossRef Medline

16. Morris E, Chalkidou A, Hammers A, et al. Diagnostic accuracy of (18)F amyloid PET tracers for the diagnosis of Alzheimer's disease: a systematic review and meta-analysis. Eur J Nucl Med Mol Imaging 2016;43:374-85 CrossRef Medline
17. Johnson KA, Sperling RA, Gidicsin CM, et al. AV45-A11 study group. Florbetapir (F18-AV-45) PET to assess amyloid burden in Alzheimer's disease dementia, mild cognitive impairment, and normal aging. Alzheimers Dement 2013;9:S72-83 CrossRef Medline

18. Aizenstein HJ, Nebes RD, Saxton JA, et al. Frequent amyloid deposition without significant cognitive impairment among the elderly. Arch Neurol 2008;65:1509-17 CrossRef Medline

19. Zukotynski K, Kuo PH, Mikulis D, et al. PET/CT of dementia. AJR Am J Roentgenol 2018;211:246-59 CrossRef Medline

20. Ryan NS, Keihaninejad S, Shakespeare TJ, et al. Magnetic resonance imaging evidence for presymptomatic change in thalamus and caudate in familial Alzheimer's disease. Brain 2013;136:1399-414 CrossRef Medline

21. Laforce R Jr, Soucy JP, Sellami L, et al. Molecular imaging in dementia: past, present, and future. Alzheimers Dement 2018;14:1522-52 CrossRef Medline

22. Villemagne VL, Okamura N. In vivo tau imaging: obstacles and progress. Alzheimers Dement 2014;10:S254-64 CrossRef Medline

23. Hyman BT, Phelps $\mathrm{CH}$, Beach $\mathrm{TG}$, et al. National Institute on Aging-Alzheimer's Association guidelines for the neuropathologic assessment of Alzheimer's disease. Alzheimers Dement 2012;8:1-13 CrossRef Medline

24. Tanpitukpongse TP, Mazurowski MA, Ikhena J, et al. Predictive utility of marketed volumentric software tools in subjects at risk for Alzheimer disease: do regions outside the hippocampus matter? AJNR Am J Neuroradiol 2017;38:546-52 CrossRef Medline

25. Yueniwati Y, Wangsadjaja C, Yulidani IG, et al. The role of brain MRI as an early detector of cognitive impairment. J Neurosci Rural Pract 2018;9:350-53 CrossRef Medline

26. No HJ, Yi HA, Won KS, et al. Association between white matter lesions and cerebral glucose metabolism in patient with cognitive impairment. Rev Esp Med Nucl Imagen Mol 2019;38:160-66 CrossRef Medline

27. Chandra A, Dervenoulas G, Politis M; Alzheimer's Disease Neuroimaging Initiative. Magnetic resonance imaging in Alzheimer's disease and mild cognitive impairment. J Neurol 2019;266:1293-1302 CrossRef Medline

28. Nasrabady SE, Rizvi B, Goldman JE, et al. White matter changes in Alzheimer's disease: a focus on myelin and oligodendrocytes. Acta Neuropathol Commun 2018;6:22 CrossRef Medline

29. Belaidi AA, Bush AI. Iron neurochemistry in Alzheimer's disease and Parkinson's disease: targets for therapeutics. J Neurochem 2016;139(Suppl 1):179-97 CrossRef Medline

30. Gao L, Jiang J, Cai Z, et al. Brain iron deposition analysis using susceptibility-weighted imaging and its association with body iron levels in patients with mild cognitive impairment. Mol Med Rep 2017;16:8209-15 CrossRef Medline

31. Hohenfeld C, Werner CJ, Reetz K. Resting-state connectivity in neurodegenerative disorders: Is there potential for an imaging biomarker. Neuroimage Clin 2018;18:849-70 CrossRef Medline

32. Li HJ, Hou XH, Liu HH, et al. Towards systems neuroscience in mild cognitive impairment and Alzheimer's disease: a meta-analysis of 75 fMRI studies. Hum Brain Mapp 2015;36:1217-32 CrossRef Medline

33. Wilson H, Pagano G, Politis M. Dementia spectrum disorders: lessons learnt from decades with PET research. J Neural Transm (Vienna) 2019;126:233-51 CrossRef Medline

34. Brown RK, Bohnen NI, Wong KK, et al. Brain PET in suspected dementia: patterns of altered FDG metabolism. Radiographics 2014;34:684-701 CrossRef Medline

35. Olney NT, Spina S, Miller BL. Frontotemporal dementia. Neurol Clin 2017;35:339-74 CrossRef Medline

36. Diehl J, Grimmer T, Drzezga A, et al. Cerebral metabolic patterns at early stages of frontotemporal dementia and semantic dementia: a PET study. Neurobiol Aging 2004;25:1051-56 CrossRef Medline

37. Grimmer T, Diehl J, Drzezga A, et al. Region-specific decline of cerebral glucose metabolism in patients with frontotemporal 
dementia: a prospective 18F-FDG-PET study. Dement Geriatr Cogn Disord 2004;18:32-36 CrossRef Medline

38. Diehl-Schmid J, Grimmer T, Drzezga A, et al. Decline of cerebral glucose metabolism in frontotemporal dementia: a longitudinal 18F-FDG-PET-study. Neurobiol Aging 2007;28:42-50 CrossRef Medline

39. Bocchetta M, Gordon E, Cardoso MJ, et al. Thalamic atrophy in frontotemporal dementia: not just a C9orf72 problem. Neuroimage Clin 2018;18:675-81 CrossRef Medline

40. Jakabek D, Power BD, MacFarlane MD, et al. Regional structural hypo- and hyper-connectivity of frontal-striatal and frontal-thalamic pathways in behavioral variant frontotemporal dementia. Hum Brain Mapp 2018;39:4083-93 CrossRef Medline

41. Sheela KR, Kesavadas C, Varghese T, et al. Assessment of iron deposition in brain in frontotemporal dementia and its correlation with behavioral traits. AJNR Am J Neuroradiol 2017;38:1953-58 CrossRef Medline

42. Farid K, Charidimou A, Baron JC. Amyloid positron emission tomography in sporadic cerebral amyloid angiopathy: a systematic critical update. Neuroimage Clin 2017;15:247-63 CrossRef Medline

43. Miller-Thomas MM, Sipe AD, Benzinger TL, et al. Multimodality review of amyloid-related disease of the central nervous system. Radiographics 2016;36:1147-63 CrossRef Medline

44. Werring DJ, Gregoire SM, Cipolotti L. Cerebral microbleeds and vascular cognitive impairment. J Neurol Sci 2010;299:131-35 CrossRef Medline

45. Jang H, Jang YK, Kim HJ, et al. Clinical significance of amyloid beta positivity in patients with probable cerebral amyloid angiopathy markers. Eur J Nucl Med Mol Imaging 2019;46:1287-98 CrossRef Medline

46. Charidimou A, Farid K, Tsai HH, et al. Amyloid-PET burden and regional distribution in cerebral amyloid angiopathy: a systematic review and meta-analysis of biomarker performance. J Neurol Neurosurg Psychiatry 2018;89:410-17 CrossRef Medline

47. Sarikaya I. PET imaging in neurology: Alzheimer's and Parkinson's diseases. Nucl Med Commun 2015;36:775-81 CrossRef Medline

48. Shams S, Fallmar S, Schwarz S, et al. MRI of the swallow tail sign: a useful marker in the diagnosis of Lewy body disease? AJNR Am J Neuroradiol 2017;38:1737-41 CrossRef

49. Eidelberg D, Moeller JR, Dhawan V, et al. The metabolic anatomy of Parkinson's disease: complementary [18F]fluorodeoxyglucose and
[18F] fluorodopa positron emission tomographic studies. Mov Disord 1990;5:203-13 CrossRef Medline

50. Webb J, Willette AA. Aging modifies the effect of GCH1 RS11158026 on DAT uptake and Parkinson's disease clinical severity. Neurobiol Aging 2017;50:39-46 CrossRef Medline

51. Patro SN, Glikstein R, Hanagandi $P$, et al. Role of neuroimaging in multidisciplinary approach towards non-Alzheimer's dementia. Insights Imaging 2015;6:531-44 CrossRef Medline

52. Bhattacharya K, Saadia D, Eisenkraft B, et al. Brain magnetic resonance imaging in multiple-system atrophy and Parkinson disease: a diagnostic algorithm. Arch Neurol 2002;59:835-42 CrossRef Medline

53. Belaidi AA, Bush AI. Iron neurochemisty in Alzheimer's disease and Parkinson's disease: targets for therapeutics. J Neurochem 2016;139(Suppl 1):179-97 CrossRef Medline

54. Thomas GE, Leyland LA, Scahrag AE, et al. Brain iron deposition is linked with cognitive severity in Parkinson's disease. J Neurol Neurosurg Psych 2020;0:1-8 CrossRef Medline

55. Surendranathan A, O'Brien JT. Clinical imaging in dementia with Lewy bodies. Evid Based Ment Health 2018;21:61-65 CrossRef Medline

56. McKeith IG, Boeve BF, Dickson DW, et al. Diagnosis and management of dementia with Lewy bodies: fourth consensus report of the DLB consortium. Neurology 2017;89:88-100 CrossRef Medline

57. McColgan P, Tabrizi SJ. Huntington's disease: a clinical review. Eur J Neurol 2018;25(1):24-23 CrossRef Medline

58. Agosta F, Altomare D, Festari C, et al. EANM-EAN Task Force for the Prescription of FDG-PET for Dementing Neurodegenerative Disorders. Clinical utility of FDG-PET in amyotrophic lateral sclerosis and Huntington's disease. Eur J Nucl Med Mol Imaging 2018;45:1546-56 CrossRef Medline

59. Gaura V, Lavisse S, Payoux P, et al. Association between motor symptoms and brain metabolism in early Huntingon disease. JAMA Neurol 2017;74:1088-96 CrossRef Medline

60. Pagano G, Niccolini F, Politis M. Current status of PET imaging in Huntington's disease. Eur J Nucl Med Mol Imaging 2016;43:1171-82 CrossRef Medline

61. Caobelli F, Cobelli M, Pizzocaro C, et al. The role of neuroimaging in evaluating patients affected by Creutzfeld-Jakob disease: a systematic review of the literature. J Neuroimaging 2015;25:2-13 CrossRef Medline 